\title{
Nonverbal communication of young players in team sports
}

\author{
Pop C.L. ${ }^{\mathrm{ABCDE}}$, Zamfir M.V. ${ }^{\mathrm{ABCDE}}$ \\ Bucharest University of Economic Studies, Romania
}

Authors' Contribution: A -Study design; B -Data collection; C -Statistical analysis; D -Manuscript Preparation; E Funds Collection.

\begin{tabular}{|c|c|}
\hline \multicolumn{2}{|l|}{ Abstract } \\
\hline Purpose: & $\begin{array}{l}\text { Nonverbal communication is always present in sport teams' competition, on the court and around the } \\
\text { court. This paper purpose is to investigate the nonverbal skills in two elite basketball cadet teams. }\end{array}$ \\
\hline Material: & $\begin{array}{l}\text { Pursuing this goal, we applied the PONS test to a group of } 38 \text { young basketball players } 15-16 \text {-year-old: } \\
20 \text { girls and } 18 \text { boys. The teenagers were members of Romanian national cadet teams having at least } \\
3 \text { years up to } 7 \text { years of experience playing basketball. The test applied to this sample was The Profile } \\
\text { of Nonverbal Sensitivity. The test results were statistically analysed aiming to evaluate the nonverbal } \\
\text { decoding accuracy of each evaluated athlete and to identify the possible differences between the two } \\
\text { teams: boys and girls. }\end{array}$ \\
\hline Results: & $\begin{array}{l}\text { There is a statistically significant difference between the two teams in boys' favor, meaning that the } \\
\text { girls have done lower average general scores. In decoding face cues both teams are almost equal, de } \\
\text { difference relay on understanding the body movement and attitude. }\end{array}$ \\
\hline Conclusions: & $\begin{array}{l}\text { Due the scores obtained by the tested players we can conclude that their nonverbal skills are at high } \\
\text { level. Training nonverbal communication potentially enhanced game planning and building into the } \\
\text { team a healthy psychological and social environment. }\end{array}$ \\
\hline Keywords: & Communication, teamwork, nonverbal sensitivity, basketball. \\
\hline
\end{tabular}

\section{Introduction}

Achieving a sport team goal relay on the cooperation with others towards a common goal. Sport team has all the characteristics of a small group: interaction, social structure (norms and rules), a common fate and a common purpose [1]. Teams in sports can have at least 2 members for table tennis or badminton, 3 for streetball, 5 for basketball, 6 for volleyball, 15 for rugby, up to 18 in Australian football teams. To achieve the game purpose, the cooperation with others is vital. The role of a sport team coach is to encourage the team members working together, teach social skills and strengthen team spirit.

During a game in a sport competition, the specific language is a code of visual and auditive gestures. The success is depending of the consolidated tactical teammates relations and synchronization of their actions. On the pressure of time and rapid development of the game, players must take tactical synchronized decisions [2]. In this context the nonverbal communication is prevalent because during the game, except the time outs, is no time for words. The connection between the teammates is meaningful in a social and occasionally in an emotional meaning too. Nonverbal communication usually carries more emotional meaning then words only. It was observed a prevalence of nonverbal communication in individual sports also. In athletics events for example, the athletes communicate nonverbally 52,14\%, while coaches respond in $50,83 \%$ of cases with gestures and body movements [3].

Nonverbal communication is a code that has the advantage to be all known, can be delivered at long distance and understood 4.5 times more rapidly than verbal communication [4]. Nonverbal messages could

\footnotetext{
(c) Pop C.L., Zamfir M.V., 2020

doi:10.15561/18189172.2020.0104
}

be encoded in gestures; eye contact; body movement like speed, direction, proximity or amplitude; attitude, body shape, facial expression; touching; etc. Mehrabian had stated that even $55 \%$ of the communication is happening via general body language [5]. Having such a wide range of signs and signals the channels that address nonverbal communication are, in fact, the five senses.

Due it's features the nonverbal communication is often present around the court not only on the court. The referee's signs and signals have meanings for competitors, coaches and audience whatever if they speak different languages [6]. Colors, numbers and marks also have significance in the convention of sport games.

The coach communication style, other than the verbal content, will determine the team working climate. An open climate will inspire trust, enjoyment and will support the athletes to maintain a good team spirit in training and competition [7]. A pleasant and supportive social environment will help sportsmen to take part enthusiastically in training sessions. Working in a friendly group, watching other people exercising, receiving constructive feed-back and assistance could motivate youngsters intrinsically to join and continue in a sport team [8].

Although the nonverbal communication is so present in sports teams training and competition, the phenomena received not enough attention. This paper purpose is to investigate the nonverbal skills in an elite basketball cadet team.

\section{Material and methods.}

Participants. Pursuing this goal, we applied the PONS test to a group of 38 young basketball players 15-16-yearold: 20 girls and 18 boys. The teenagers were members of Romanian national cadet teams having at least 3 years up 
to 7 years of experience playing basketball.

Research Design. The test applied to this sample was The Profile of Nonverbal Sensitivity -PONS test, translated and adapted in Romanian language. According to Ambady, La Plante, \& Johnson, (2001) the PONS is useful in examining individual differences in interpersonal sensitivity as well as detecting differences in channels of communication [9].

Originally this test was designed to measure one's ability to decode nonverbal cues from the face, body, and voice $[10,11]$ and contained a sequence of 220 video images with sound. For our research purpose we chose one of the three short forms of the test consisting in 40 images of face and body without sound. The scenes were displayer on a screen for 3 seconds with 3 seconds brake, used for choosing the correct answer from two possibilities. The answer sheet provides two possible answers reflecting an emotional state, and the participant selects what she or he believes is the most appropriate answer [12]. Each item was scored as correct or incorrect. The reference rank for nonverbal competence level is the following:

- $\quad$ under 20 points -low nonverbal competence;

- 20-25 points -average score;
- $\quad$ above 25 points - high nonverbal competence [13].

Statistical Analysis. The test results were statistically analysed aiming to evaluate the nonverbal decoding accuracy of each evaluated athlete and to identify the possible differences between the two teams: boys and girls. We used Microsoft Excel program for analyzing data and graphical representation.

\section{Results}

The scores obtained by the players in the research sample are mostly high. The average mark could be considered an exception in boys' sample; just one of 18 , representing 5.6\%, scored Average. In girls' case the Average mark appeared 4 time out of 20 tested subjects, representing $20 \%$.

Girls' total mean score was $27.85 \pm 2.71$. The sample homogeneity is high: $\mathrm{CV}=9.73 \%$ having a narrow range meaning the mean value is informative. On the face images section girls scored $13.1 \pm 1.68$ while on body images they obtained as mean value $14.9 \pm 1.89$.

Boys' total mean score was $29.5 \pm 2.43$, higher than girls' results. The sample homogeneity is better: $\mathrm{CV}=$ $8.23 \%$ having also a narrow range meaning the mean

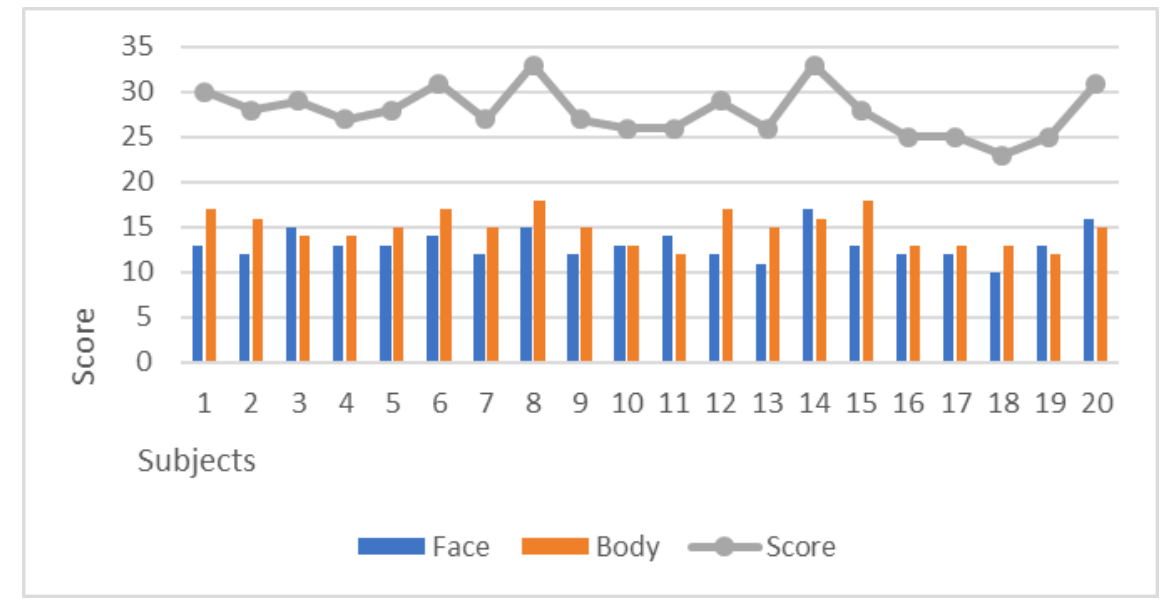

Fig. 1. PONS test results -girls' team

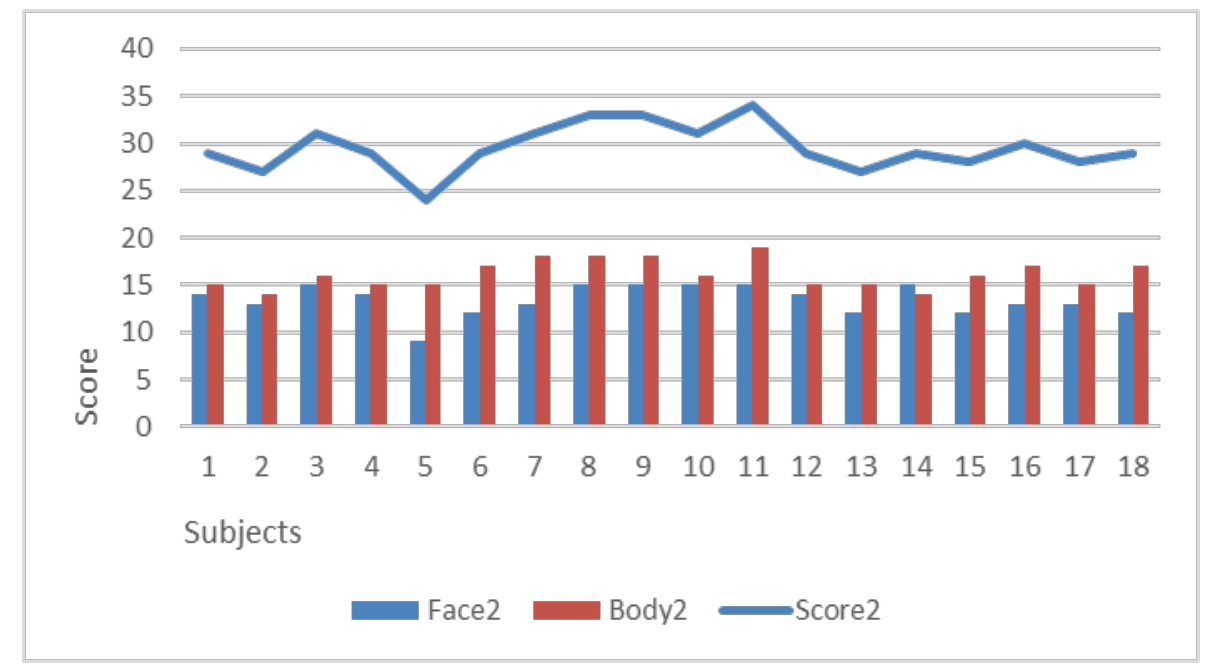

Fig. 2. PONS test results -boys' team 
Table 1. Analysis of variance

ANOVA

\begin{tabular}{lllllll}
\hline Source of Variation & SS & df & MS & F & P-value & F crit \\
\hline Between Groups & 25.79211 & 1 & 25.79211 & 3.851963 & 0.057452 & 3.487303 \\
Within Groups & 241.05 & 36 & 6.695833 & & & \\
Total & 266.8421 & 37 & & & & \\
\hline
\end{tabular}

value is informative. On the face images section boys scored $13.4 \pm 1.61$, slightly better than girls. In body images boys responded correctly in $16.1 \pm 1.49$ cases.

The difference in total score between the two teams was of 1.65 points. Using ANOVA single factor, we find a statistically significant difference between the two research groups in PONS total score in favor of boys: $\mathrm{F}$ $(1,36)=3.85, \mathrm{p}=0.057$.

\section{Discussions}

Most athletes in our sample have proven a high nonverbal sensitivity. Twenty-one of twenty-four studies showed positive correlation between high score in PONS total score and several positive personality traits. Those who score higher in PONS seems to be more extraverted and popular, more interpersonally encouraging, less dogmatic and more interpersonally sensitive as judged by acquaintances and supervisors $[14,15]$. All those traits are an advantage for a player in any team not only in sport teams.

The tested players are members of Romanian national cadet teams, presuming to have the proper skills for sport performance and being the best in their generation. One of the fewest study which evaluate nonverbal sensitivity in competitive sport performance states that winning players tend to score higher in PONS test. Compering to the defeated athletes, the winning ones are more sensitive to nonverbal cues and their communication patterns are more homogenous and reliable [16].

A large body of evidence suggests that body language is under both conscious, deliberate control, and under unconscious, autonomous control. Contextual influences like score pressure, hostile supporters or fatigue could unbalance the nonverbal cues from conscious toward unconscious control [17, 18].

Studies has been equivocal with respect to gender differences in communication [19]. In our sample there is a significant difference between boys and girls. Although men and women are mostly similar in terms of nonverbal communication, gender seems to play a role in our social interactions. Women are used to reveal emotion through facial expressions more frequently and more accurately than men, while men are thought to hide their emotions [20]. Although there is the stereotype that women communicate better, in our research case young men seems to read better body language and to be more sensitive to nonverbal cues.

\section{Conclusions}

Due the scores obtained by the tested players we can conclude that their nonverbal skills are at high level. There is a statistically significant difference between the two teams in boys' favor, meaning that the girls have done lower average general scores. In decoding face cues both teams are almost equal, de difference relay on understanding the body movement and attitude. In basketball, anticipating the opponent and teammates intentions are crucial to winning the ball and points. The anticipation of the next action is based on the understanding of the way and direction the observed body moves. Therefore, this specific PONS parameter has greater importance for a basketball player than the massages sent at face level.

In order to effectively solve the problems that may arise during a match, the basketball team resembles a well-regulated mechanism powered by subtle energy. That creative energy is expressed by a group whose strength and abilities are greater than the sum of individual qualities of team members. This synergy is based on each one's feeling of belonging to a team. The team is built on interpersonal relationships and team spirit develops through open and enhanced communication channels between teammates. Among those channels in sport teams, basketball in our study, the nonverbal communication plays a key role in solving common game tasks.

We consider PONS test a useful diagnose instrument for tactical training of young athletes in all team sports, not only in basketball. Nonverbal communication can no longer be ignored, it's components potentially enhanced communication and game planning aiming to build into the team a healthy psychological and social environment.

\section{Conflict of interest}

The authors have declared no conflict of interest. 
1. Tuckman BW, Jensen MAC. Stages of SmallGroup Development Revisited. Group \& Organization Studies, 1977;2:419-27. https://doi.org/10.1177/105960117700200404

2. Zamfir MV. Verbal and non-verbal communication in sport environment. Marathon, 2017: 9(1): 99-106.

3. Rata G, Rata BC, Rata M, Mares G, Melinte M. Verbal and nonverbal communication during hammer throw training and competitions. Ovidius University Annals, Series Physical Education and Sport /Science, Movement and Health, 2012; 12(2 Suppl.):370-375.

4. Pop CL, Zamfir MV. Optimazing Communication in Team Sports. Bucuresti: Ed. Pro Universitaria; 2017. (in Roumanian)

5. Mehrabian A. Silent messages. Wadsworth, California: Belmont; 1971.

6. Pop CL. Improving Interpersonal Communication for a Higher Quality of Physical Activities. Procedia - Social and Behavioral Sciences, 2014; 116(21):4983-4987. https://doi.org/10.1016/j.sbspro.2014.01.1059

7. Pop CL. Communication in Physical Education and Sport. Bucuresti: Ed. Pro Universitaria; 2014. (in Roumanian)

8. Pop CL. Individual and Collective Levels in Teambuilding through Physical Education. In: Runcan P, Rata G, Gavreliuc A, editors. Applied Social Sciences: Psychology, Physical Education and Social Medicine, Cambridge Scholars Publishing; 2013. P. 217-224.

9. Ambady N, LaPlante D, Johnson E. Thin-slice judgments as a measure of interpersonal sensitivity. In: Hall JA, Bernieri FJ, editors. Interpersonal sensitivity: Theory and measurement. Hillsdale, NJ: Erlbaum; 2001. P. 89-101.

10.Rosenthal R, Hall JA, DiMatteo MR, Rogers PL, Archer D. Profile of Nonverbal Sensitivity (PONS Test): 2013 [cited 2019 Aug 22]. Available from: https://repository.library. northeastern.edu/downloads/neu:rx914607j?datastream id $=$ content

11.Rosenthal R, Archer D, Hall JA, DiMatteo MR, Rogers PL. Measuring sensitivity to nonverbal communication: the pons test. Nonverbal Behavior, Elsevier; 1979, p. 67-98. https://doi.org/10.1016/B978-0-12-761350-5.50012-4

12.Janusik LA. Profile of Nonverbal Sensitivity (PONS): (Rosenthal, Hall, DiMatteo, Rogers, \& Archer, 2013). In: Worthington DL, Bodie GD, editors. The Sourcebook of Listening Research, Hoboken, NJ, USA: John Wiley \& Sons, Inc.; 2017, p. 522-9. https://doi.org/10.1002/9781119102991.ch58

13.Gheorghe M, Alina M, Marian ZV, Laurențiu T. Nonverbal Communication in the Romanian Male and Female Representative Basketball Teams -U16. Procedia Social and Behavioral Sciences, 2014;117:288-94. https://doi.org/10.1016/j.sbspro.2014.02.215

14. Andersen PA. Nonverbal Communication: Forms and Functions. Mountain View, CA: Mayfield, 1999.

15. Rosenthal R, Hall JA, DiMatteo MR, Rogers PL, Archer D. Sensitivity to nonverbal communication: The PONS test. Baltimore, MD: The Johns Hopkins University Press; 1979.

16.Domagoj Lausic, Selen Razon, Gershon Tenenbaum. Nonverbal sensitivity, verbal communication, and team coordination in tennis doubles. International Journal of Sport and Exercise Psychology, 2015, 13(40): 398-414. https://doi.org/10.1080/1612197X.2014.993681

17.Furley P, Schweizer G. Nonverbal communication of confidence in soccer referees: an experimental test of Darwin's leakagehypothesis.J.SportExerc. Psychol.2017.38:590-597. https://doi.org/10.1123/jsep.2016-0192

18.Furley P. The Social Synapse in Sports Interpersonal Coordination and Nonverbal Behavior in Sports. Complex Systems in Sport, International Congress. Linking Theory and Practice. 2017; 47-49. [cited 2019 Aug 24]. Available from: https://www.researchgate.net/publication/321331313_The Social_Synapse_in_Sports_Interpersonal_Coordination_ and Nonverbal_Behavior_in_Sports

19. Bull SJ. Sport Psychology: A Self-help Guide. Ramsbury: Crowood Press; 1999.

20.Sullivan P. Communication differences between male and female team sport athletes. Communication Reports, 2004; 17(2): 121-128. https://doi.org/10.1080/08934210409389381

\section{Information about the authors:}

Pop C. L.; (Corresponding author); Professor PhD; http://orcid.org/0000-0002-6445-8702; crispotir@yahoo.com; Physical Education and Sport Deparment, Bucharest University of Economic Studies; No 6 Romana Square, Bucharest, Romania.

Zamfir M. V.; Assistant prof. PhD; http://orcid.org/0000-0001-9422-6884; crispotir@yahoo.com; Bucharest University of Economic Studies; No 6 Romana Square, Bucharest, Romania.

Cite this article as:

Pop CL, Zamfir MV. Nonverbal communication of young players in team sports. Pedagogy of physical culture and sports, 2020;24(1):26-29.

https://doi.org/10.15561/18189172.2020.0104

This is an Open Access article distributed under the terms of the Creative Commons Attribution License, which permits unrestricted use, distribution, and reproduction in any medium, provided the original work is properly cited (http://creativecommons.org/licenses/by/4.0/deed.en).

Received: 16.09 .2019

Accepted: 25.10.2019; Published: 10.11.2019 